\title{
Private voluntary standards in livestock and meat sectors: Implications for developing countries
}

\author{
DIEGO NAZIRI and BEN BENNETT
}

Over recent decades, international trade in meat products has increased enormously. Developing countries have had a leading role in the recent dynamics of the meat sector and have witnessed the strongest growth in consumption, production, and international trade. International trade in food products is governed by a growing array of public and private food standards. In recent decades, private voluntary standards developed in Western countries have become a key element of governance in meat food chains. The proliferation and influence of these private standards may represent both an opportunity and a threat for livestock producers and, in the coming years, might have increasingly important developmental implications for poorer countries, including those in sub-Saharan Africa. The purpose of this work is to shed light on the current practice in the application of these standards and to examine the present and future implications for developing countries, especially in Africa.

Keywords: private voluntary standards, trade, meat, livestock, smallscale producers, developing countries, SSA

INTERNATIONAL TRADE IN FOOD PRODUCTS is governed by a growing array of public and private food standards. In recent decades, private voluntary standards (PVS) developed in Western countries have become key elements of governance in global agro-industrial food chains. International trade in meat products is no exception.

Several studies have addressed the issue of the impact of private standards on developing countries and, within them, on smaller producers. While considerable knowledge already exists on the role, functioning, and impact of PVS in other sectors of the food market, such as fresh fruit and vegetables and traditional commodities such as coffee, tea, and cocoa, there is a paucity of such studies in the meat sector.

The purpose of this work is to help fill this gap in the literature by analysing current practice in the application of these standards. The focus is on private standards in the EU market. The main opportunities

Diego Naziri, PhD, is Market and Trade Economist and Ben Bennett is Head of the Food and Markets Department at the Natural Resources Institute of the University of Greenwich, UK.

(C) Practical Action Publishing, 2012, www.practicalaction.org doi: 10.3362/2046-1887.2012.006 ISSN: 2046-1879 (print) 2046-1887 (online) 


\section{A distinction is drawn between standards developed by retailers and those developed by NGOs}

Over 65 per cent of the rural population participates in livestock-related activities in ACP countries

Rapid income growth and urbanization are driving growth in demand for meat and threats are identified for both developing countries as a whole and for specific actors in the supply chain within the countries. Even though recently the two categories have blurred, a distinction is drawn between standards developed by grocery retailers and industry groups, and standards addressing environmental, animal welfare, social, and ethical issues traditionally developed by non-governmental organizations (NGOs). Emphasis is given to the different impact that the two categories of private standards might have on the actual and potential export opportunities of developing countries, with particular attention to those in sub-Saharan Africa (SSA).

In order to carry out the study, an extensive literature review was conducted. Additional information has been provided by some key informants involved in the international meat trade as either importers or exporters.

\section{The global meat market and implications for development}

In order to grasp the possible implications of the proliferation of PVS for developing countries and small-scale producers, it is important to understand the recent trends in the global meat market in terms of consumption, production, trade, and potential opportunities to increase trade.

Livestock contribute 40 per cent of the global value of agricultural output. In terms of the importance of livestock to poor households in the developing world, it has been estimated that animal production supports the livelihoods and food security of almost a billion people (FAO, 2009). In African, Caribbean, and Pacific (ACP) countries, over 65 per cent of the rural population participates in livestock-related activities and livestock keeping contributes, on average, 14-30 per cent of the agricultural GDP. Livestock also contributes to nutritional security, provides farm inputs such as draught power and manure, serves as investment sinks and sources of cash income in times of need, as providers of transport, and, in some communities, as an important form of social capital (FAO, 2009).

Consumption of livestock products has increased rapidly in developing countries over the past decades. Rapid income growth and urbanization, combined with underlying population growth, are driving growth in demand for meat and other animal products. The greatest increases have occurred in East and Southeast Asia and in Latin America and the Caribbean (FAO, 2009). Consumption of livestock products per capita in developing regions is still substantially lower than in the developed world with potential for significant increases. Developing countries have responded to growing demand for livestock products by rapidly increasing production. In 1995, for 
Between 1980 and 2006 the total volume of meat exports increased from 10 to 32 million tonnes
Most of the increase in meat consumption and production is expected in developing countries

Most of the growing livestock demand has been met by large-scale production the first time, more meat was produced in developing than developed countries, and by 2007 it was estimated that 60 per cent of meat was produced in developing countries (Perry and Dijkman, 2010). Trends in production growth largely mirror those for consumption, with China and Brazil showing the greatest growth. Production of meat also increased in SSA but more slowly than in other regions.

The evolution of the meat trade in recent decades has been very dynamic. Between 1980 and 2006, the volume of total meat exports increased more than threefold (from 10 to 32 million tonnes) and the share of production entering international trade grew significantly. Around 90 per cent of livestock products, however, is still consumed within the country of production and does not enter international trade. Currently, international trade is dominated by a small number of players and just nine countries/trading blocs accounted for 96 per cent of beef exports in 2008: Brazil, Australia, USA, India, New Zealand, Canada, Argentina, Uruguay, and the EU (IMS, 2009). Since mid-2002, developing countries as a whole have been net exporters of meat (FAO, 2009) but if exports from Brazil, China, India, and Thailand are excluded, all developing regions are net importers of meat. A particular source of concern is the net trade position in livestock products of the least-developed countries (LDCs). These countries are increasingly dependent on imports of livestock products to meet growing demand. Livestock exports remain of minimal importance to the poorest countries: Africa exports about 1 per cent of the world's total meat volume and this proportion has been declining in recent years.

According to projections from OECD-FAO (2009), most of the increase in global meat consumption and production is expected to occur in developing countries ( 82 per cent and 87 per cent of projected global growth, respectively). A handful of major exporters, including the United States, Canada, Argentina, Australia, and Brazil, will remain the dominant traders in world markets. Import dependency is expected to grow both in the $\mathrm{EU}$ and in many developing countries.

Worldwide, most of the growing livestock demand has been met by commercial large-scale livestock production. This tendency is likely to continue in the future. Recently, we have witnessed a rapid growth in the average size of primary production units and a shift towards fewer and larger farms in many parts of the world (FAO, 2009). A growing divide is emerging; large-scale industrial producers serve dynamic growing markets whereas traditional pastoralists and smallholders, while often continuing to support local livelihoods and provide food security, are unlikely to benefit from the rising market opportunities, and risk further marginalization.

Moreover, in order to access lucrative markets in the developed world, recognition of freedom from several transboundary animal diseases, 
Standards set by the food industry aim to facilitate their supply chain management

Standards developed by NGOs

typically aim to reward sustainable and ethical practices such as foot and mouth disease (FMD), is needed. Currently in Africa, the World Organization for Animal Health (OIE) recognizes FMD-free zones only in Botswana, Namibia, South Africa, and Swaziland (in these countries the stringency of mandatory sanitary and phytosanitary (SPS) standards has contributed to further widening the gap between small livestock keepers and large commercial producers). In many developing countries the eradication of FMD is not technically or economically feasible and, accordingly, many African countries have started to show growing interest in selling their meat products to markets where public standards are less strict: domestic, regional, and, possibly, emerging Asian markets where demand for livestock products is projected to increase considerably in the next decades.

\section{Proliferation of private standards in the livestock and meat sectors}

The OIE defines PVS as 'commercial requirements developed, owned, and implemented by non-governmental entities, such as private companies or NGOs, with which suppliers must comply to have access to specific markets' (OIE, 2010: 691). In 2007, UNCTAD estimated the number of private schemes governing food industry at 400 and rising (Wolff and Scannell, 2008).

These standards are highly variable with respect to their purpose and their scope, the nature of the standard owners, and the rules and procedures that govern their development and implementation. PVS set by the food industry, either by individual companies or by industry groups, typically aim at product differentiation and at facilitating their supply chain management. PVS developed by NGOs typically address environmental and social issues and aim to reward sustainable and ethical practices.

PVS set by the food industry are not mandatory and suppliers are not required by law to meet them. The retailer scheme may be de facto applied, however, as the industry norm by all actors in the supply chain. Thus the choice of whether or not to comply with a PVS becomes a choice between compliance or exit from the market.

Since this study addresses the development implications of the proliferation of PVS for trade in meat products from the poorest countries, it specifically focuses on beef. In fact, beef is the only meat product that is significantly exported by SSA countries even though almost exclusively by Namibia and Botswana.

In view of major health crises that have occurred in Europe, in particular the BSE (bovine spongiform encephalopathy) crisis, food safety has become one of the most important aspects of quality for both consumers and retailers. Retailers use PVS to demonstrate 'due diligence' to satisfy increasingly stringent EU food safety legislation, 
Livestock products represent the highest risk to health and consequently face the highest level of regulation

European retailers have a strategy of private differentiation from public minimum standards but they are also turning to them as a marketing tool by addressing consumers' preferences (Sans et al., 2005). Accordingly, in order to be responsive to consumers' needs, PVS aim at reducing the risks associated with food consumption, as perceived by consumers. The concept of perceived risk rather than objective risk is viewed by consumer behaviourists as being more powerful than objective risk in explaining consumer purchasing behaviour (Fearne et al., 2001).

According to a study by the European Commission (2010), residues such as antibiotics or hormones in meat represent the second source of concern after pesticide residues in fruit, vegetables, or cereals. The introduction of PVS throughout the supply chain can be viewed as a strategic response by the beef industry to these concerns. While PVS were initially introduced in order to minimize the effect of consumers' risk perception associated with inconsistent quality, the focus of such schemes has shifted over time to food safety. In particular, consumers' difficulties in evaluating food safety pave the way for policies of differentiation (Sans et al., 2005).

Compliance with PVS is demanded more where supermarkets' share of meat sales is larger, particularly in the UK. Furthermore, in the UK, unlike other EU countries, fresh meat is almost exclusively own branded and, as such, the category is seen as a key factor in major supermarkets' attempts to differentiate themselves from competitors.

Private firms arguably have the greatest incentive to implement PVS where there are inadequate (or perceived as such) public food safety and/or quality standards; here PVS act as a substitute for missing public institutions or inspection services (Henson and Reardon, 2005). Public minimum quality standards (MQS) also affect the type of PVS developed by the industry. Livestock products represent the highest level of risk to human and animal health and consequently face the highest level of public regulation of international trade. As argued by Codron et al. (2005), the capacity of governments to put in place credible monitoring systems made it possible and attractive for retailers to implement individual strategies of differentiation These may be based on the creation of product segments providing guarantees of quality higher than public MQS and sold as private-label products. In the fruit and vegetable sector, the differentiation into higher-than-MQS produce is more recent and less developed than in the case of beef. In the fruit and vegetable sector, retailers focus on establishing a private minimum standard and refuse to differentiate their products by safety levels. Rather they build their private labels on commercial characteristics and, above all, gustatory quality of produce, which is still the main expectation of the consumer. Hence, while in the case of beef, European retailers have focused so far on a strategy of private differentiation from a public MQS, in the fruit and vegetable sector they have moved more towards development 


$\begin{array}{r}\text { Retailers have } \\ \text { broadened } \\ \text { standards to include } \\ \text { ethical issues and } \\ \text { target consumers } \\ \text { who pay premiums } \\ \text { for these products } \\ \hline\end{array}$

of a collective standard for safety (e.g. GLOBALGAP), acting as a quasi-MQS, as an insurance strategy to protect all retailers from a safety shortfall that would damage them all together.

Furthermore, consumers are increasingly interested in embedded values such as the ethical dimension of food quality. This concept includes a wide range of social, environmental, or cultural issues such as the treatment of workers, a fair return to producers, environmental impacts of production, and animal welfare. PVS addressing these issues were originally developed by NGOs in order to add value to the products and, unlike PVS developed by business operators, they are not a basic requirement for selling to specific buyers. More recently, retailers and food businesses have either developed new PVS, or broadened the scope of PVS initially developed to address food safety, in order to cover these additional issues and target those consumers prepared to pay considerable premiums for products that meet their expectations.

Many PVS now address a combination of issues (environmental, social, food safety, and quality). Different objectives and target markets have led to the development of a broad array of PVS. The next section presents some of these standards and offers a picture of their features and scope.

\section{An overview of private standards in the livestock and meat sectors}

PVS can exceed international public standards, official import requirements, and requirements for domestic production. While PVS put greater emphasis on process rather than product standards, the latter still play an important role in food control. In general, collective PVS designed to be adopted by organizations in different countries do not incorporate 'private' microbiological criteria, but refer to those established by the relevant national authority. For example, the GLOBALGAP livestock standards contain microbiological criteria for zoonosis monitoring in primary production, but these are in line with the international standards set by the OIE. Conversely, some individual company standards include microbiological criteria that might be considered more stringent than national regulation and put a considerable additional burden on suppliers (e.g. requirements for absence of Listeria spp. in some raw meat products; OIE, 2010; WTO, 2009).

In the area of animal health, PVS currently have a very limited scope. This is mainly due to the reluctance or inability of private standardsetting bodies to provide assurances on animal health. This is an area where assurances can only be provided by an official competent authority (CA), because of the sophisticated nature of animal disease 
Private standards are reacting very rapidly to consumers' changing demands in the meat sector surveillance systems and the controls in place. Currently the animal health status of live animals and animal products in international trade is certified exclusively by the CA, taking as a basis the relevant provisions set by the OIE. There is no accepted alternative to this official certification and PVS cannot therefore replace or substitute it (Wolff and Scannell, 2008).

Where the multilateral framework is not up-to-date, including in relation to consumer demands, there is a possibility that PVS will fill the vacuum. Most respondents (72 per cent) to a survey on PVS circulated by the OIE agree that PVS in international trade of livestock products have arisen because of a lack of official standards in some areas (OIE, 2010). An example is animal welfare, where consumers are increasingly insistent on high standards. Some suggest that the MQS in animal welfare should be stricter in order to narrow the gap to be filled by PVS (Roberts, 2008). Some others question whether public standards should go beyond ensuring compliance with basic safety and hygiene standards and whether higher quality levels and other values, including animal welfare, should be the preserve of PVS (Perry and Dijkman, 2010).

PVS are reacting very rapidly to consumers' changing demands in the meat sector. Although the mass market is for cheap, convenient products, a minority of more discerning, usually more affluent consumers are prepared to pay considerable premiums for products that meet their expectations, not only with regard to higher quality but also their environmental and ethical concerns. For example, 80 per cent of Norwegian consumers claim to be willing to pay more for high animal welfare beef. In the US and Canada consumer willingness to pay for higher welfare has been estimated at between 16 and 19 per cent (Caswell and Joseph, 2008). Accordingly, PVS that ensure organic/natural, socially responsible production, animal welfare, and environmental credentials are increasingly critical. According to the International Meat Secretariat (2009), PVS in the near future are expected to expand particularly in three areas: animal welfare, nutrition/human health (obesity, saturated fats), and climate change.

In 2010 FAO circulated a questionnaire on standards, codes of conduct, and guidelines in the livestock sector to obtain a picture of the current situation. The main results are presented in Box 1.

Meat suppliers willing to access markets of the developed world may be required to comply with several private standards. Table 1 presents a non-exhaustive list of PVS for livestock products. Some have been expressly developed for livestock products whereas others do not specifically target these products but they are included. These standards can be categorized according to different criteria. 
Box 1. FAO survey on private standards, codes of conduct, and guidelines in the livestock sector

- Most standards in the livestock sector address meat followed by milk and eggs.

- $56 \%$ of standards apply at national and $44 \%$ at international level, and $16 \%$ a combination of both.

One-quarter of standards are not based on national or international regulation or standards. A large majority of the standards may possibly exceed, but are unlikely to be inconsistent with, the international ones.

- $42 \%$ of standards address corporate clients, and $27 \%$ address final consumers.

- The majority of standards are developed by private business, also in cooperation with national government organizations.

Most standards cover a wide range of topics, from food safety to societal and environmental concerns, such as animal welfare, food security, environmental sustainability, worker health and safety, and nutritive values.

Source: FAO, 2010

The WTO (2007) identify three main categories of PVS required by retailers and the food industry: 1) collective international standard, usually designed by international retailers and processing companies associations (e.g. GLOBALGAP, SQF, IFS); 2) collective national standards set by national organizations, usually industry associations and producers associations (e.g. BRC, ABM, QS); and 3) companyspecific standards that are developed by individual retailers or catering firms (e.g. Tesco, Marks \& Spencer, McDonald's).

PVS in the meat sector can be included in two further categories. The first refers to the added-value standards developed by NGOs. The second refers to the standards developed by the International Organization for Standardization (ISO) that are a mixture of both public and private sector standards and, as such, they are not the main focus of this study.

Some private standards cover the whole supply chain

Others cover only one pre-farm-gate or post-farm-gate stage

PVS encompass different stages of the supply chain: some cover the whole supply chain from primary production to processing and, sometimes, up to the retailing business (e.g. ABM, QS, McDonald's). Others cover only one stage of the supply chain, either the pre-farmgate (e.g. GLOBALGAP IFA, SQF 1000, SAN) or post-farm-gate stage (e.g. BRC, IFS, SQF 2000). Some PVS are intended as business-tobusiness (B2B) tools (e.g. GLOBALGAP, BRC, Tesco Beef basic standard) while others are intended to channel information to the consumers through a label or logo (e.g. ABM, QS, and all standards for organic production whose requirements might be stricter than the official $\mathrm{EU}$ standard for organic production and labelling). 


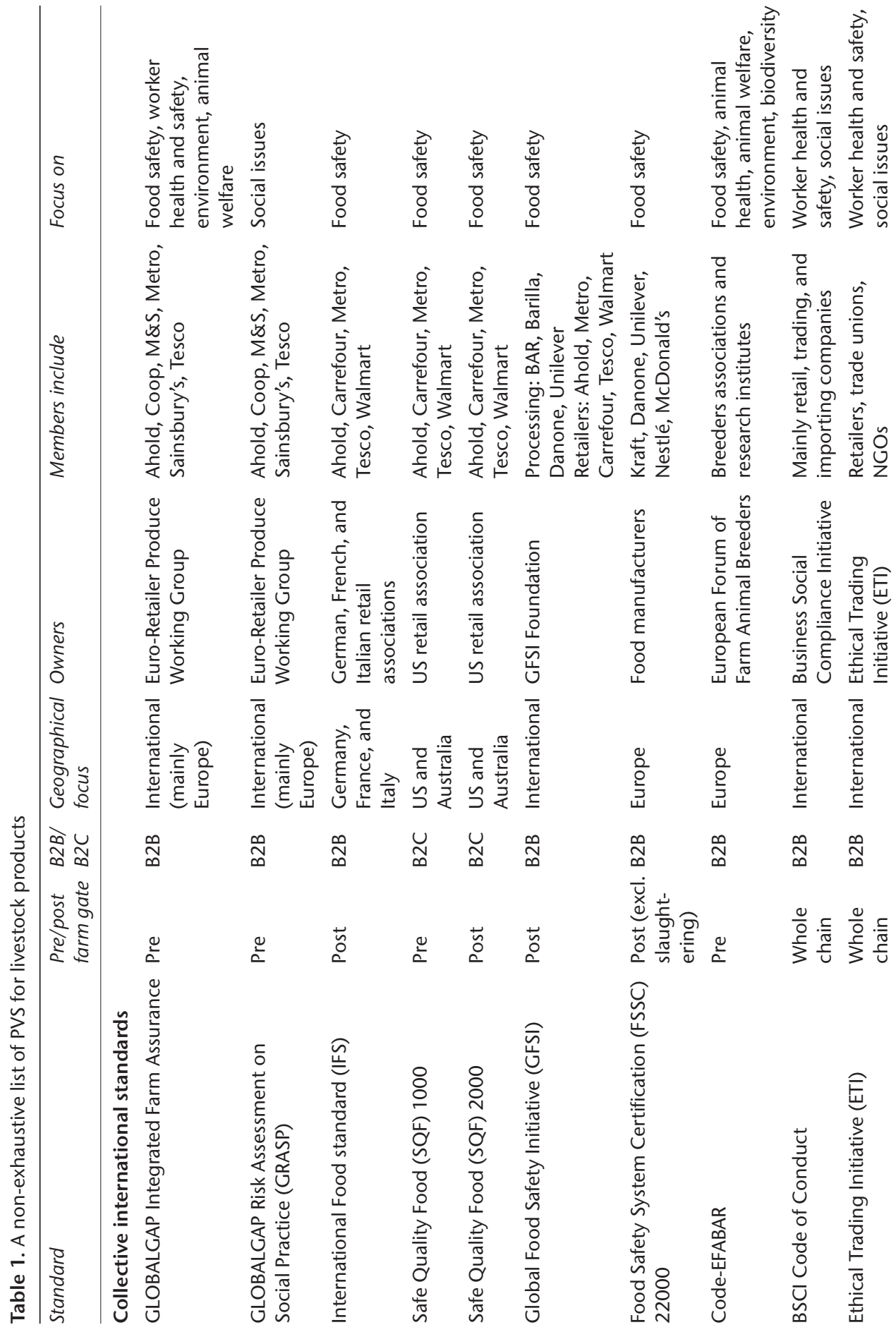




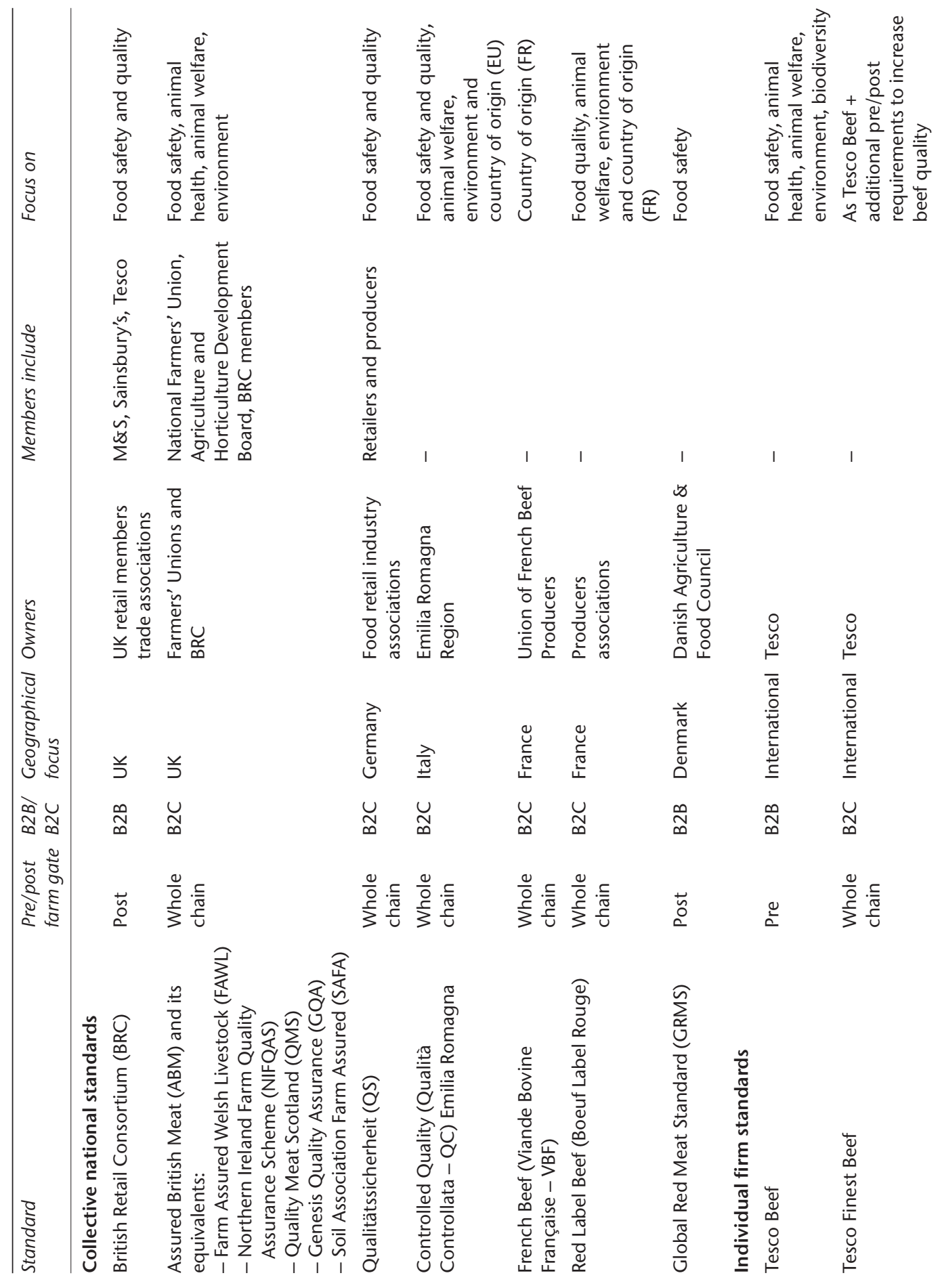




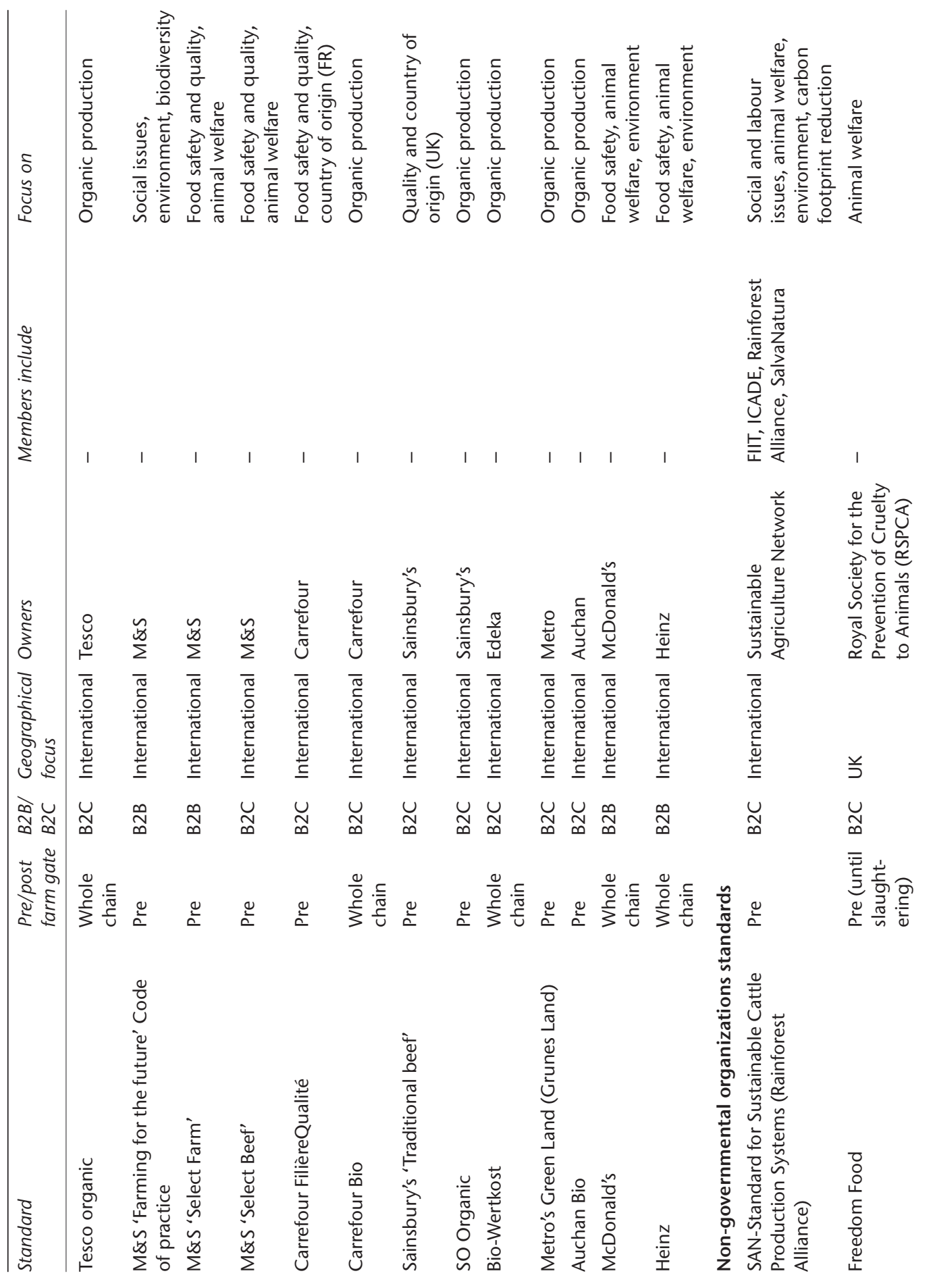




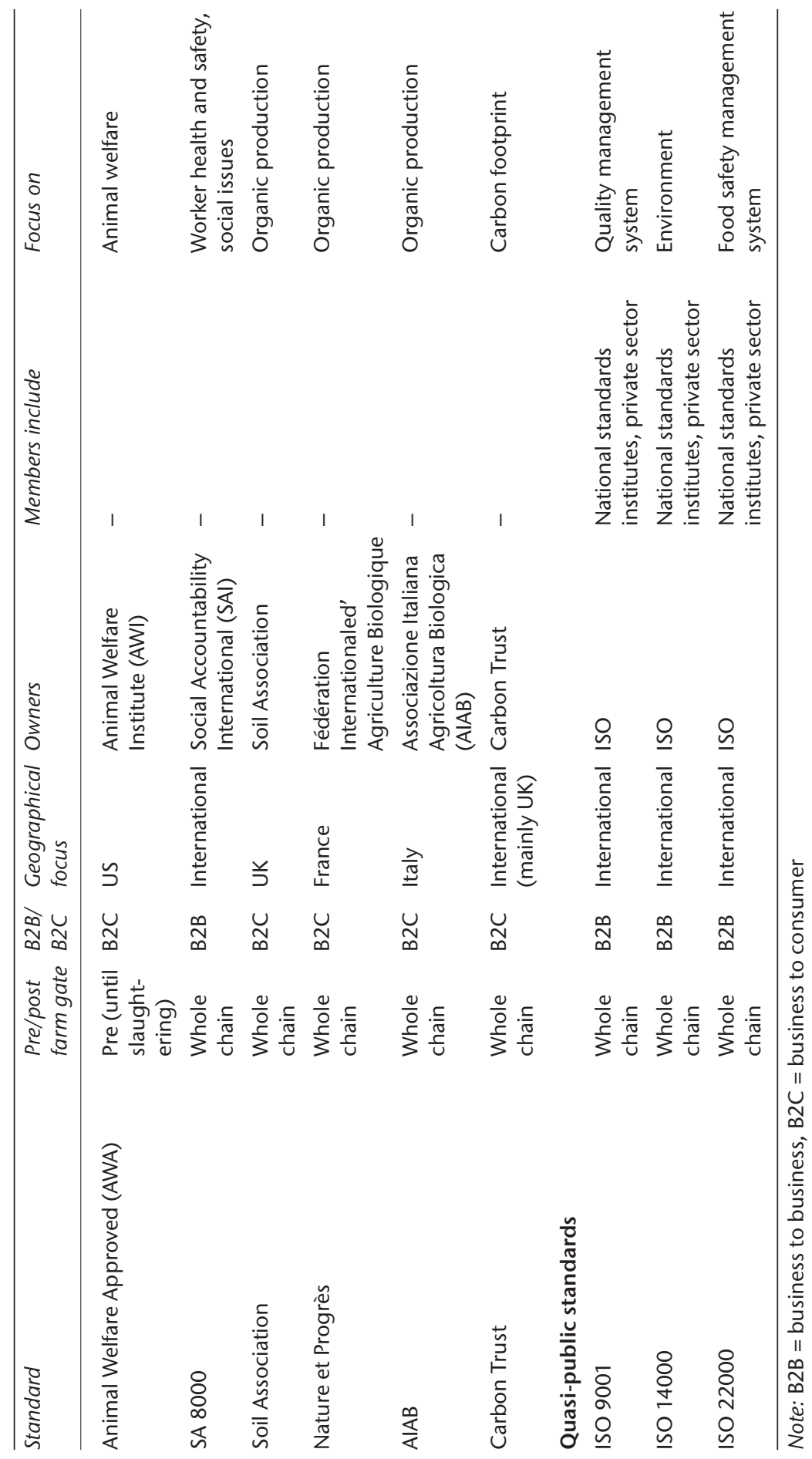


GLOBALGAP is taking a more holistic approach to livestock production
Some supermarkets segment their meat offer and sell either generic products that must meet their basic standard, or high quality labelled meat that has to comply with additional requirements. For example, while the Tesco Beef basic standard goes beyond the national farm assurance schemes (ABM and its equivalents) only for requirements in livestock transport and lairage construction, the Tesco Finest Beef standard requires additional care in order to increase the meat quality. Consumers' purchasing behaviour and quality perception (and the willingness to pay for that) vary across and within countries and this may lead to different differentiation strategies by retailers. For instance, in France, Carrefour sells 40 per cent of beef as a generic product and 60 per cent as high quality labelled meat (Carrefour Filière Qualité) while Auchan's share of generic product is higher and a small space is dedicated to differentiated products (Codron et al., 2005). Besides retailers, other buyers have begun to require compliance with these PVS (see Box 2).

A further distinction can be made between standards that focus exclusively on food safety (e.g. SQF, GFSI) and those that cover primarily social issues (e.g. ETI, SA 8000), environmental issues (e.g. all the standards for organic production), or animal welfare issues (e.g. Freedom Food, Animal Welfare Approved).

Some standards initially developed to address food safety have broadened their scope to cover additional issues. For example, GLOBALGAP is taking a more holistic approach to livestock production by including environmental and social responsibility as well as a strong emphasis on animal welfare: 44 per cent of control points focus on food safety, 26 per cent on animal welfare, 12 per cent on workers' welfare, and 9 per cent on both traceability and environment (Mainon, 2010). Moreover, the Euro-Retailer Group is developing two new GLOBALGAP standards for livestock: (1) the Compound Feed Manufacturing standard to manage the risk in manufacturing, handling, and supplying feed to livestock producers; and (2) the Livestock Transport Standard to guarantee welfare-friendly conditions for animals during transport.

\section{Box 2. PVS spread to catering sector}

Even though the bulk of eco-certified products is sold by supermarkets, it is interesting to note that the catering industry is also starting to be involved. In 2009 the value of the organic catering and restaurant sector in the UK was estimated at $£ 16.5 \mathrm{~m}$ (Soil Association, 2010). Moreover, in 2008 the Soil Association launched the Food for Life Catering Mark, an alternative to full organic catering certification. The Catering Mark is an accreditation scheme to recognize caterers that serve food with specific characteristics, including meat produced according to high animal welfare standards. 
Strengthening of the trend towards local foods is making it harder for overseas suppliers to compete
A number of PVS have, or may have in the future, significant relevance to international trade, since buyers may demand them of overseas producers. A number of PVS require that meat comes from animals that are reared, slaughtered, processed, and packed in a particular country or region (for example, France for Viande Bovine Française and the EU for Qualità Certificata Emilia Romagna). Other PVS, such as the national collective assurance schemes in the UK, are not limited to UK products but, in practice, there is no non-UK fresh meat certified for these standards. Another example is Geographical Indications that are specifically designed to establish claims about products from particular countries or regions, but their analysis is beyond the scope of this article. Accordingly, this formal or actual bar for non-national products has an indirect impact on meat exporters since it narrows their market opportunities. The recent strengthening of the trend towards local foods is making it harder for overseas suppliers to compete. This tendency is propelled by rising concerns about climate change and the impact of long distance supplies (especially air-freighted products). For example, the Carbon Trust standard, particularly important in the UK market, aims to reduce carbon emissions in both production and transportation. So far no meat product has obtained the Carbon Trust certification. Similarly, in spite of the growing proportion of consumers demanding products that contribute to increased opportunities for developing country producers, the market does not currently offer Fairtrade livestock products, unlike coffee, cocoa, fruit, or tea. One reason may be the limited share of livestock products imported from developing countries.

\section{Threats and opportunities of private standards in the livestock and meat sectors}

Several studies address the issue of the impact of PVS on trade and markets. The WTO (2005) does not give a clear picture and suggests that standards can be both trade creating as well as trade hindering. On the other hand, a major theme in the literature is the potential negative impact of PVS on trade in agricultural and food products, reflecting the increasing recognition of the importance of non-tariff measures for international trade. A number of intergovernmental bodies (including FAO/WHO, OIE, WTO, UNCTAD, and OECD) have raised concerns about the impacts of PVS, especially on developing countries attempting to exploit potentially lucrative markets for their agricultural and food products (World Bank, 2005). Moreover, it is argued that they might further marginalize weaker economic players, including small and medium-sized businesses, and smallholder farmers (World Bank, 2005; Liu, 2009). 
The main problem associated with private standards is the cost of compliance

$87 \%$ of developed countries consider private standards to have created significant benefits...

...but only $30 \%$ of developing countries see real or potential benefits
There is a paucity of empirical studies on the impact of PVS on market access opportunities of meat-exporting countries and on developmental implications of their proliferation for poorer countries. In order to partially fill this gap, OIE and FAO have recently circulated questionnaires to identify the main problems and benefits created by PVS in the livestock and meat sector (FAO, 2010; OIE, 2010). Furthermore, some additional relevant information is provided by the responses to the WTO questionnaire on PVS that, while not specifically addressing the livestock sector, have indicated that meat, along with fresh fruits and vegetables, is among the exported products most affected by SPS-related PVS (WTO, 2009). The responses to these questionnaires point to the ambivalent effect of PVS: they sometimes create problems to market access and sometimes create opportunities.

On the one hand, most respondents to the OIE questionnaire (82 per cent) agreed with the general statement that PVS for sanitary safety either have created or may create significant trade problems for exports. In this regard, opinions of developed and developing countries do not show significant discrepancy. Both the OIE and the FAO questionnaires have identified the main problem associated with these PVS as the cost for compliance, mainly for auditing, certification, and record-keeping. Respondents to the questionnaires also mentioned the lack of price premium, lack of standards' harmonization, lack of evidence-based risk assessment, lack of transparency, inadequate consultation with relevant stakeholders, and the overprescriptive nature of PVS. Beyond the problem already mentioned of complying with the requirements for Listeria spp., other examples of problems are BSE-related requirements concerning the age of animals from which meat is obtained, bluetongue requirements, and the difficulty arising from the use of veterinary drugs that are not necessarily approved or registered in the import market (WTO, 2009; FAO, 2010). A few respondents to the WTO questionnaire specifically mention PVS negatively affecting their meat exports: Argentina reported BRC, ISO 22000, Heinz, and McDonald's standards; China reported BRC, IFS, GLOBALGAP, and Tesco standards; and Brazil reported GLOBALGAP, BRC, and UFAS standards (the UFAS standard applies to the feed industry). The current work to develop a GLOBALGAP standard for feed may indicate a future proliferation of PVS in this area. Such a trend would represent a further source of concern for several small producers in developing countries.

On the other hand, 62 per cent of respondents to the OIE questionnaire considered that private standards for sanitary safety have created or may create significant benefits, but there are significant differences; 87 per cent of developed countries against only 30 per cent of developing countries see real or potential benefits. The benefits that are most commonly mentioned are 'market access 
opportunities including niche markets', 'filling the policy gap left by lack of relevant international standards', and 'facilitating the implementation of public standards'.

With regard to animal welfare standards, 46 per cent of respondents agree that private animal welfare standards create or may create problems, while 47 per cent disagree. Again, the responses of developed and developing countries are quite different: most developed countries (76 per cent) disagree that PVS for animal welfare create or may create problems while most developing countries (87 per cent) see problems. The problem most mentioned is the lack of harmonization between different PVS, while compliance costs seem less important than for SPS-related standards. Examples of problems in this area are transport requirements, slaughter requirements, and stocking density. Again the proliferation of standards related to livestock transport, such as the GLOBALGAP LTS, may further exacerbate these problems.

Overall, 64 per cent of respondents consider that private animal welfare standards create or may create benefits. Again, nearly all developed countries ( 89 per cent) could see benefits of these standards but 40 per cent of developing countries do not agree. The benefits that are most commonly mentioned for PVS for animal welfare are basically the same as for SPS-related PVS.

The International Federation of Agricultural Producers (IFAP) stresses that PVS on animal welfare may have significant effects on international trade by creating additional and unjustified barriers to exports from developing countries. But IFAP has also expressed the view that PVS may facilitate better marketing of farmers' livestock products and have the potential to reward them with better returns (IFAP, 2010). In fact, even though little attention is often given to livestock welfare in many developing countries, the specificities of their production systems may give them a competitive edge over more developed countries. For example, extensive systems where livestock graze natural pasture are the rule in most developing countries and they can facilitate not only compliance with PVS for animal welfare but also provide developing countries with a competitive advantage in meeting the demand of other niche markets. In particular they can better comply with other added-value standards developed by NGOs for environmentally friendly production, such as PVS for organic farming and low carbon emission production (if Carbon Trust labels emerge in the meat sector, their impact on beef exporting developing countries will depend on a trade-off between low-emission production systems and long-distance air-freight transportation). A concern over pastoral systems is that although there are undoubtedly merits associated with livestock found in these systems, to qualify for accreditation these systems would need to be inspected on the 
Standards that are well established in industrialized countries are fast pervading developing country agri-food markets basis of specific criteria for certification. Such a process is likely to be extremely complicated, if not impossible (Perry and Dijkman, 2010).

So far, the few well-resourced countries that dominate the international beef trade have been able to comply with emerging PVS required by the market. Among the South American giants, Uruguay was already able to successfully conclude the GLOBALGAP benchmarking process for the national scheme 'Certified Natural Meat Program' and Brazil is on the way.

\section{The impact of private standards on African countries}

While several African countries are active in global trade in fruits, vegetables, and fish products, very few export livestock products to developed countries. These few countries in southern Africa are those that not only were able to maintain FMD-free zones but also have national herd sizes adequate to support reliable and sustained exports, and adequate institutional architecture to support exportorientated activities (World Bank, 2005). Since the export of livestock products from Africa is very small and limited to these few countries, the current impact of PVS must be limited as well.

It is difficult to separate out the specific impact that PVS might have on beef exports from developing countries from a range of other factors. According to Perry and Dijkman (2010), PVS do not at present play any discernible role in livestock commodities from Africa. Above all, they are not directly relevant to poor livestock producers. A major reason is that such producers cannot meet current public EU SPS standards. Cost of PVS compliance may be negligible in comparison not only to costs required for compliance with SPS import requirements but also to costs (e.g. input and services) required to access the EU market competitively in terms of quality and price. Accordingly, PVS set by the developed world's retailers cannot be currently considered a major problem for most developing countries excluding the few that are currently exporting to the EU.

In countries not presently able to access the EU market, the only concern about PVS in livestock production is that they might also be adopted at domestic and regional levels within the continent where major opportunities exist in the foreseeable future. In fact, even though their legal requirements are less strict, there is evidence that PVS, which are well established in industrialized countries, are fast becoming a global phenomenon, and pervading developing country agri-food markets (Henson and Reardon, 2005). Thus, PVS might potentially act as a barrier to access even to these markets. Conversely, as presented in the following section, southern African countries currently exporting to the EU, mainly Namibia and Botswana, are directly affected by the rise of PVS in the developed world. Whatever 
the extent of the impact of PVS on trade opportunities of African countries, it is important to explore their developmental implications. PVS can have a disproportionate effect on smallholders since small-scale African producers are unlikely to be able to afford their certification and implementation costs (even though some might manage to obtain and maintain certification by forming associations). The consequence could be a further marginalization of smaller producers. Hence, proliferation of PVS is likely to induce or exacerbate the ongoing processes of consolidation and concentration in the livestock sector (FAO, 2010).

\section{Implications of private standards for the Namibian beef sector}

Namibia and Botswana are the only significant African countries supplying the EU beef market. So far only a few large EU retailers and processing companies have required compliance with specific PVS as a condition to purchase beef originating from Namibia.

The proliferation of post-farm-gate standards is not a particular source of concern, and they are unlikely to affect the Namibian export potential since the main exporter, MeatCo (a parastatal organization taking over 80 per cent of the export market), has good financial and human resources to comply with them. Apart from the ISO 9001 and HACCP certifications for food quality and food safety systems which MeatCo has held since 2000, from April 2010 it has been accredited by the British Retail Consortium (BRC), whose standards include benchmarks for production, packaging, storage, and distribution of safe food, animal welfare, corporate social responsibility, and ethical labour policies. A BRC audit is conducted annually by the international, independent auditing firm SAI Global. Additionally MeatCo is subject to the requirements of a number of premium clients including ASDA and Tesco in the UK, Swedish and Danish Co-ops, Norsk Polar in Norway, and Heinz - including Heinz baby food which has some of the strictest food safety and quality standards in the world (MeatCo is one of the few companies in the world selected to supply ingredients for Heinz baby food). These buyers not only demand the highest standards in food quality and safety, but also place strong emphasis on aspects that encompass primary production such as social responsibility, animal welfare, sound environmental practices, and fair labour practices. Some of them require compliance with the BSCI Code of Conduct, while Tesco and Swedish supermarkets demand producers to meet the terms of their individual schemes. In order to meet these requirements, Namibia had to implement a costly Farm Assured Namibian Meat Scheme (FAN Meat), the first of its kind in Africa. This quality assurance scheme covers aspects of animal health 


$\begin{array}{r}\text { Farm-assured meat } \\ \text { gives the Namibian } \\ \text { beef industry a } \\ \text { trade advantage } \\ \text { because EU markets } \\ \text { pay premium prices } \\ \hline\end{array}$

and welfare, good farming practices, and the traceability of livestock. The FAN Meat scheme is administered by the Meat, Board of Namibia and certified by the country's Directorate of Veterinary Services. The existence of this scheme resulted in Namibia's ability to comply with private standards demanded by retailers in both Europe and South Africa. Following the implementation of FAN Meat, the Namibian beef industry has increased market leverage and has a trade advantage over its competitors because EU markets often pay premium prices for the country's products.

The Namibian meat sector now wants to obtain certification for organic meat production. Beef in Namibia generally comes from free-range cattle and thus already has a good international reputation. Namibia is already about 90 per cent compliant with international requirements for organic meat (P. Strydom, General Manager, Meat Board of Namibia, pers. comm.). It is anticipated that by targeting niche markets, organic meat production and marketing could bring in additional income to the meat industry, including livestock producers (Chander et al., 2011).

MeatCo is also endeavouring to meet the GLOBALGAP livestock standard through SAI Global. FAN Meat has not yet been benchmarked against GLOBALGAP and this might represent a barrier to selling to some buyers in the EU. According to the information collected from key informants, however, compliance with this standard is not yet commonly required by EU buyers of African beef.

Access to the EU market is barred for livestock producers in the Northern Communal Areas (NCA) because of the presence of FMD. Unlike the FMD-free southern part of the country where livestock production is a well-developed, capital-intensive, and export-oriented industry, agricultural practices in the NCA, where around 60 per cent of Namibia's population resides, are a mixture of transhumance and sedentary agro-pastoral systems. The current main market destination for beef produced by MeatCo in NCA is South Africa where it is predominantly used by the manufacturing industry. As such, PVS required by EU retailers do not have any direct implication for the poorest part of the Namibian population (in fact the FAN Meat scheme is not implemented in the NCA). There is serious concern, however, that PVS adopted by EU retailers may soon spread among retailers and processing industries in South Africa. Small-scale producers in the NCA are unlikely to be able to comply with pre-farm-gate PVS and the government would struggle to support hundreds of thousands of livestock keepers (in the FMD-free zone 1 million cattle are raised by just 4,000 large producers). This would mean the loss of access to the main destination market and this may have serious developmental implications for an area where marketing options are extremely limited. 


\section{Conclusions}

\section{Private standards reflect growing public and media interest in food provenance}

Private standards are likely to exacerbate consolidation and concentration in the livestock sector
The global meat trade is increasingly pervaded by a plethora of PVS set either by retail and industrial groups or by NGOs. While PVS were initially developed by retail and industrial groups in order to minimize the effect of consumers' risk perception associated with inconsistent quality, the focus of such schemes has changed over time to reflect consumers' changing risk perceptions and growing public and media interest in food provenance.

Giant grocery retailers were the main drivers of PVS development and, not surprisingly, PVS are more widespread where supermarkets have a larger share of meat sales, particularly in the UK. Compliance to PVS is often a condition to sell to these buyers and it is, de facto, increasingly becoming mandatory to access the EU market.

PVS may represent both threats and opportunities for livestock producers. Even though developing countries seem more affected by PVS, the present impact is likely to be rather small. On the one hand, meat exports from developing countries are dominated by a small number of well-resourced countries that so far have proved capable of complying with PVS required by the EU market. On the other hand, livestock exports remain of minimal importance to the poorest countries. Moreover, most SSA countries are not able to access the EU market since they cannot meet current public EU SPS standards. The SSA countries that may be directly affected by the rise of PVS in the developed world are the few southern African countries currently exporting to the EU, mainly Namibia and Botswana. While the current impact of PVS on livestock producers in Africa is limited, the situation is likely to change in the coming years. First, compliance with PVS will increasingly become a key requisite to access Western markets. Second, PVS, similar to those set for more developed countries, might spread in developing countries' markets such as South Africa and the Middle East where major opportunities exist because of less strict legal requirements and strong growth of demand. Third, PVS are likely to also be adopted in the catering sector where they have so far been used considerably less than in the retail sector. Finally, current work to develop private standards for feed and livestock transportation may indicate a future proliferation of PVS in these areas.

A particular source of concern is the spread of pre-farm-gate PVS that are likely to exacerbate the ongoing processes of consolidation and concentration in the livestock sector and to further widen the gap between small livestock keepers and large commercial producers. As shown by the example of Namibia, although PVS might further marginalize smaller producers from the international trade in livestock products, larger, reputable and well-resourced companies that are able to comply with PVS of the destination market might benefit from 
This can further widen the gap between small livestock keepers and large commercial producers them. Even though little attention is often given to livestock welfare in many developing countries, the specificities of their production systems may give them a competitive edge over more developed countries, particularly in extensive cattle production systems. As such, PVS may fuel processes of poverty reduction and development through contributions to national GDP and employment opportunities. Moreover, PVS can have spill-over effects since such larger companies have the potential to serve as role models, helping to build domestic markets and processing infrastructures for the provision of higher quality and safer food products (Perry and Dijkman, 2010). In the context of poverty reduction initiatives targeted at developing countries, it is important to consider the wide range of potential poor beneficiaries. These are not just confined to smallholder producers, but also poor consumers, and of course the various other players in the livestock value chains such as marketers and slaughterhouse and processing plant employees.

\section{References}

Caswell, J.A. and Joseph, S. (2008) 'Consumer demand for quality: Major determinant of agricultural and food trade in the future', Journal of International Agricultural Trade and Development 4(1): 99-116.

Chander, M., Subrahmanyeswari, B., Mukherjee, R. and Kumar, S. (2011) 'Organic livestock production: An emerging opportunity with new challenges for producers in tropical countries', Scientific and Technical Review of the Office International des Epizooties 30(3): 969-983.

Codron, J.M., Giraud-Héraud, E. and Soler, L.G. (2005) Minimum quality standards, premium private labels, and European meat and fresh produce retailing. Food Policy 30(3): 270-283 <http://dx.doi.org/10.1016/j.foodpol. 2005.05.004>.

European Commission (2010) Food Related Risks, Special Eurobarometer No. 354, EC, Brussels.

FAO (2009) The State of Food and Agriculture 2009: Livestock in the Balance, FAO, Rome.

FAO (2010) Draft Report on a Global Survey on Private Standards, Codes of Conduct and Guidelines in the Livestock Sector, FAO, Rome.

Fearne, A., Hornibrook, S. and Dedman, S. (2001) 'The management of perceived risk in the food supply chain: A comparative study of retailer-led beef quality assurance schemes in Germany and Italy', International Food and Agribusiness Management Review 4: 19-36 <http://dx.doi.org/10.1016/ S1096-7508(01)00068-4>.

Henson, S. and Reardon, T. (2005) 'Private agri-food standards: Implications for food policy and the agri-food system', Food Policy 30(3): 241-253 <http:// dx.doi.org/10.1016/j.foodpol.2005.05.002>.

IFAP (2010) Farm Animal Welfare and Private Standards, IFAP, Paris. 
International Meat Secretariat (IMS) (2009) Developments in the Global Meat Market, IMS, Rome.

Liu, P. (2009) Private Standards in International Trade: Issues, Opportunities and Long-Term Prospects, FAO, Rome.

Mainon, D. (2010) GLOBALGAP Livestock: Demand and Supply Trends, GLOBALGAP, London.

OECD-FAO (2009) Agricultural Outlook 2009-2018, OECD Publishing, Paris.

OIE (2010) Final Report: OIE Questionnaire on Private Standards, OIE, Paris.

Perry, B. and Dijkman, J. (2010) Livestock Market Access and Poverty Reduction in Africa: The Trade Standards Enigma, FAO, Rome.

Roberts, M.T. (2008) Private Standards in the Global Food Sector: Relationship with the WTO Agreements, National Agricultural Law Center, Arkansas.

Sans, P., de Fontguyon, G. and Briz, J. (2005) 'Meat safety as a tool of differentiation for retailers: Spanish and French examples of meat "supply chain brands"', International Journal of Retail \& Distribution Management 33(8): 618-635 <http://dx.doi.org/10.1108/09590550510608403>.

Soil Association (2010) Organic Market Report 2010 [website], Soil Association, Bristol <http://www.soilassociation.org/LinkClick.aspx?fileticket=bTXno01M $\mathrm{TtM}=\&$ tabid=116> [accessed 25 January 2011].

Wolff, C. and Scannell, M. (2008) Implication of Private Standards in International Trade of Animals and Animal Products, OIE, Paris.

World Bank (2005) Food Safety and Agricultural Health Standards: Challenges and Opportunities for Developing Country Export, World Bank, Washington, DC.

WTO (2005) World Trade Report 2005, WTO, Geneva.

WTO (2007) Private Standards and the SPS Agreement, WTO, Geneva.

WTO (2009) Effects of SPS-related Private Standards: Descriptive Report, WTO, Geneva. 